\title{
Schwere Entscheidungen bei der Hyposensibilisierung
}

\author{
Autoimmunkrankheiten gelten als generelle Kontraindikation für \\ eine Hyposensibilisierung. Eine Leserin fragt an, wie in Konflikt- \\ situationen verfahren werden sollte.
}

$\mathrm{D}$ ie spezifische Immuntherapie (SIT) mit Insektengiften ist eine sichere und wirksame Therapie. Patienten mit anaphylaktischen Reaktionen sollten wenn irgend möglich diese Therapie erhalten. Langjährige Erfahrungen haben die Allergologen überzeugt, dass auch bei Patienten in hohem Alter und mit hohem kardialem Risiko keine erhöhte Nebenwirkungsrate besteht und somit diese $\mathrm{Pa}$ tientengruppe effektiv behandelt werden kann. Durch den rasanten Zuwachs an molekularbiologischem Wissen bezüglich immunologischer Erkrankungen sowie der Wirkmechanismen der SIT kommen wir allerdings zunehmend in Gewissenskonflikte. Ich möchte mein Problem an zwei Beispielen erläutern und mit den Lesern des Allergo Journal diskutieren.

Fall 1: 52-jährige Patientin, 20 Minuten nach Wespenstich in den Oberarm entwickelten sich Quinckeödem, generalisierte Urtikaria, Atemnot. Wenige Minuten später trat Bewusstseinsverlust ein.

Der titrierte Intradermaltest mit Wespengift zeigte bei $0,01 \mu \mathrm{g} / \mathrm{ml}$ eine Quaddel $\geq 5 \mathrm{~mm}$; spezifisches Serum- $\mathrm{IgE}$ gegen Wespengift war CAP-Klasse 3, gegen Bienengift CAP-Klasse 0; Serumtryptase $9,2 \mu \mathrm{g} / \mathrm{ml}$.

Es besteht somit eine klare Indikation zur SIT. Die Patientin wird allerdings wegen einer rheumatoiden Arthritis mit dem TNF- $\alpha$-Hemmer Infliximab und Leflunomid behandelt. Leflunomid verhindert die Synthese von Pyrimidin, greift damit in den DNA- und RNAStoffwechsel ein und blockiert die Zellteilung aktivierter Lymphozyten. Meine Fragen dazu sind:

1. Die rheumatoide Arthritis ist die häufigste Form der Gelenkentzündung und kommt bei $0,5-1 \%$ der Bevölkerung vor. Auch wenn die Entzündungsmechanismen nicht vollständig geklärt sind, besteht Konsens darüber, dass $\mathrm{CD}^{+}{ }^{+}$-Lymphozyten, und hier besonders der TH1-Subgruppe, eine Schlüsselrolle zukommt. Die regulatorischen T-Zellen unterscheiden sich funktionell im Vergleich zu denen gesunder Personen nicht, sie sind auch in ihrer Anzahl nicht vermindert. Durch die SIT wird über regulatorische T-Zellen die Balance zwischen TH1und TH2-Lymphozyten zur TH1-Dominanz verändert. Muss ich davon ausgehen, dass ich durch die SIT die Rheumatoidarthritis aktiviere?

2. Können die genannten Medikamente die Wirksamkeit der SIT reduzieren? Wie könnte Leflunomid auf die Aktivität der TH2-Lymphozyten wirken?

Fall 2: 45-jährige Patientin, 15 Minuten nach Wespenstich in einen Finger traten generalisierter Juckreiz, nach etwa 30 Minuten Atemnot mit Ruhedyspnoe, Schwindelgefühl, Diarrhoe, Urtikaria und Lippenschwellung auf.

Der titrierte Intradermaltest mit Wespengift zeigte bei $0,01 \mu \mathrm{g} / \mathrm{ml}$ eine Quaddel $\geq 5 \mathrm{~mm}$; spezifisches Serum- $\mathrm{IgE}$ gegen Wespengift war CAP-Klasse 2,

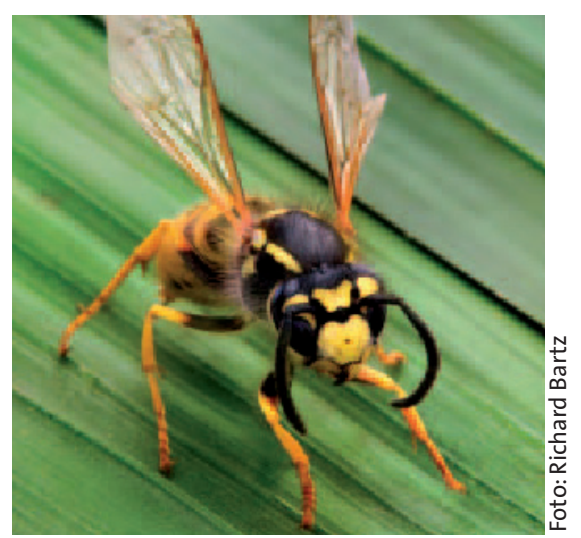

Was wiegt schwerer: Das Risiko des nächsten Stichs oder die Sorge vor der Progredienz einer Autoimmunkrankheit? gegen Bienengift CAP-Klasse 0; Serumtryptase $3,2 \mu \mathrm{g} / \mathrm{ml}$.

Es besteht auch bei dieser Patientin eine klare Indikation zur SIT. Die Patientin wird aber wegen einer Wegenerschen Granulomatose mit Cyclophosphamid und Prednisolon behandelt. Meine Fragen dazu sind:

1. Besteht die Möglichkeit, dass durch die SIT eine Wegenersche Granulomatose aktiviert wird? Sollte man, wie bei Tumorerkrankungen, ein beschwerdefreies Intervall und Therapiepausen fordern?

2. Kann die SIT unter der genannten Medikation unwirksam sein, weil die regulatorischen T-Zellen durch die Therapie mit Cyclophosphamid eher supprimiert als aktiviert werden?

Beide Patienten erhalten von mir bislang keine Insektengift-SIT. Würden auch Sie so entscheiden? Wenn nicht - warum? Welche Erwägungen würden Ihre Entscheidung beeinflussen?

\section{Dr. Uta Rabe}

Abteilung für Asthma und Allergologie, Johanniter-Krankenhaus Treuenbrietzen, Johanniterstraße 1, 14929 Treuenbrietzen E-Mail: rabe@johanniter-treuenbrietzen.de

\section{Stellungnahme}

A utoimmunkrankheiten gelten, wie auch z. B. aktive Tumorleiden oder chronische Infekte, generell als Kontraindikationen für die SIT [2]. Angesichts der zwei geschilderten Patientinnen mit bedrohlichen Reaktionen auf Wespenstiche sowie nachgewiesener Sensibilisierung auf Wespengift bei aktiver rheumatoider Arthritis bzw. Wegenerscher Granulomatose unter Behandlung mit Infliximab und Leflunomid bzw. Cyclophosphamid und Prednisolon gerät man als behandelnder Allergologe jedoch in einen Entscheidungsnotstand und stellt sich die Frage nach der wissenschaftlichen Begründung dieses Kontraindikationen-Verdiktes.

Wie Frau Dr. Rabe erwähnt, werden Autoimmunkrankheiten allgemein als TH1-gewichtete, IgE-vermittelte Allergien dagegen als $\mathrm{TH} 2$-gewichtete immunologisch bedingte Krankheiten angesehen. Ziel der Pharmakotherapie von Autoimmunkrankheiten mit Medikamen- 